\title{
Analysis of Tenodesis Techiques for treatment of Scapholunate Instability using the Finite
}

\section{Element method}

\section{INTRODUCTION}

The scapholunate interosseous ligament (SLIL) is a strong C shaped ligament which maintains stability at the SL joint. Injury to the SLIL is one of the most frequent causes of carpal instability and accounts for a considerable degree of wrist dysfunction, absence from work, and interference with activities due to the key role of SL joint in the kinematic behaviour of the wrist [14]. The incidence of scapholunate instability associated with acute wrist injuries was found to be $5 \%$ in a study undertaken by Jones [12] of 100 consecutive patients who presented with wrist sprains; this figure may be much higher $(30 \%)$ when a distal radius fracture is also present [9].

Based on the severity, SLIL injuries are generally categorized into six stages and various surgical options have been described for the treatment at each stage [14]. For patients with non-repairable SLIL but with a reducible SL dissociation, ligament reconstruction autografts is an option. Earlier reported SLIL reconstructions, the Brunelli tenodesis method and its modifications $[5,8,24]$, used a distally based portion of flexor carpi radialis graft to pass through a bone tunnel in the scaphoid from volar to dorsal, which was then fixed to the distal radius or certain restraining ligaments. Such techniques can only stabilize the SL joint at the dorsal region thus volar opening may occur. Although improved pain scores at midterm follow-up are achievable with these reconstructions, the long-term outcomes are still indeterminate [14]. New treatments continue to be proposed for improvement. Corella et al. [6] described a technique to augment the dorsal SLIL reconstruction with a volar SLIL reconstruction using lunate and scaphoid tunnels created in the sagittal plane. Lee et al. [18] proposed a scapholunate axis method (SLAM) by augmenting the dorsal SLIL reconstruction with a central axis tethering of the scaphoid and lunate through the bone tunnels in the coronal plane. The performances

This is the author manuscript accepted for publication and has undergone full peer review but has not been through the copyediting, typesetting, pagination and proofreading process, which may lead to differences between this version and the Version of Record. Please cite this article as doi: $10.1002 / \mathrm{cnm} .2897$ 
of SLAM and modified Brunelli tenodesis (MBT) have been compared in vitro, with results indicating that SLAM improves SL interval and SL angle correction compared with MBT under a clenched fist posture [18].

In the current study, the ability of MBT, Corella and SLAM techniques to restore the stability of SL joint was investigated through finite element (FE) analysis. For this purpose, five 3-D FE models of the wrist simulating intact (ligament), SLIL sectioning, MBT, Corella and SLAM reconstructions were developed. The predicted SL gaps at both dorsal and volar sides as well as the SL angle of these models under an ulnar deviated clenched fist posture were obtained for comparison purposes. The FE wrist models of anatomical wrist and SLIL sectioning were validated by comparing predicted SL dorsal gap and angle in the neutral position and the ulnar deviated clenched fist posture with corresponding values obtained from in vitro cadaveric tests. Following this validation, the reconstruction technique simulations were run for comparison purposes.

\section{MATERIALS AND METHODS}

\subsection{FE Modelling}

Computer tomography (CT) scan images of the right wrist, showing no sign of abnormality, from a 63 year old female volunteer were used for construction of the 3-D FE model. From the scan, 133 CT image slices were generated, with thickness of $0.7 \mathrm{~mm}$ and transverse resolution of $512 * 512$, covering the distal radius and ulna to the proximal portion of the metacarpals. The images were imported into the ScanIP image processing software (Simpleware Ltd, Exeter, UK) and resampled with pixel spacing of $0.4 \mathrm{~mm} * 0.4 \mathrm{~mm} * 0.4 \mathrm{~mm}$ to optimize the element size as well as the mesh quality. The 3-D surface models of cortical bone for each of the 15 bones were reconstructed using a thresholding method and manual segmentation where necessary. The surface representations of the cortical bones 
were then imported into Abaqus 6.14 (Dassault Systemes, RI, USA) individually for solid mesh generation using linear tetrahedral elements (C3D4), with the space enclosed by the internal layer of the cortical bone being meshed as cancellous bone. The meshed bone representations were then assembled in Abaqus to form the wrist model.

Cartilage layers for the articulations between bones were modelled with wedge elements (C3D6) by identifying the articulating surfaces on the external layer of cortical bone and offsetting outwardly with a thickness value of half the minimum gap between the two articulating bones $[1,10]$. Thirty one ligaments involved in carpal bone motion, including 10 extrinsic ligaments, 16 intrinsic ligaments and 5 interosseous ligaments were incorporated into the model. The dorsal radiocarpal ligament, dorsal intercarpal ligament and volar radioscaphocapitate ligaments were modelled with shell elements (Figure 1(a)) to simulate the wrapping of these ligaments around the bone structures they cover while all the other ligaments were modelled with two-node spring elements. The insertion points as well as the cross section areas were based on anatomic studies [2, 19]. To avoid stress concentrations, each ligament modelled with spring elements was represented by multiple elements to distribute the force over the attachment area. The final model consisted of 353,578 elements and 79,815 nodes (Figure 1(a)). The coordinate system was set to be consistent with that of the wrist in the neutral position, in which the longitudinal axis of radius was aligned vertically with the $\mathrm{Z}$ axis, while the $\mathrm{X}$ axis was perpendicular to the $\mathrm{Z}$ axis and parallel with the transverse axis of the forearm when the radial styloid process and the ulnar styloid process were overlapped laterally [15] (Figure 1(a)).

The bones and cartilages were assumed to be homogeneous and isotropic. A Young's modulus of 18,000MPa and 100MPa was assigned for the cortical bone and cancellous bone, respectively [1, 10, 11], both of which were assumed to exhibit linear elastic behaviour. For Poisson's ratio, the cortical 
bone and cancellous bone were assumed to have values of 0.2 and 0.25 , respectively $[1,10,11]$. The cartilage was defined as hyper-elastic material, for which the Mooney-Rivlin parameters C10 and C01 were assigned as 4.1 and 0.41 , respectively $[1,10]$. The ligaments were defined as tension only, with stiffness ranging from 10 to $325 \mathrm{~N} / \mathrm{mm}$ (see Table 1), values which were based on the literature $[1,7$, 21]. For the three ligaments meshed with shell elements, the stress-strain relationships were calculated from their stiffness and the corresponding cross section areas [19]. Figure 1(b) and (c) shows the hand structures included in the model in dorsal and volar views.

For all the articulations involving proximal carpal bones, surface-to-surface contacts were established to allow free movement of scaphoid, lunate and triquetrum. For the remaining articulations, tie constraints were defined as it has been determined that the distal carpal bones are tightly bound to one another and that the motion between them can be considered to be negligible [13]. The detailed interactions between the articulations are listed in Table 2.

Based on the intact (ligament) wrist model, four additional models were constructed to simulate the wrist joint following SLIL virtual sectioning and after application of the three tendon graft reconstruction techniques (Figure 2). As shown in Figure 2(b), the scaphoid and lunate were fully connected with SLIL in the intact model. For the SLIL sectioning model, the SLIL was totally removed so there was no connection between the scaphoid and lunate (Figure 2(c)). Following the descriptions of the modified Brunelli tenodesis (MBT) technique [8], a hole of 3mm in diameter was produced through the scaphoid bone from palmar tuberosity to a dorsal point of insertion of the dorsal SLIL. The tendon graft passed through the hole from volar to dorsal side and connected to the lunate bone at dorsal region (Figure 2(d)). For the Corella method [6], besides the hole drilled in the scaphoid bone, as in the MBT method, a second hole was drilled in lunate from dorsal to volar at the 
medial region (Figure 2(e)). The tendon graft connected the two bones from both dorsal and volar regions by passing through the scaphoid and lunate in sequence [6]. Unlike the first two methods, the holes drilled in the scaphoid and lunate in the SLAM method [18] were along the coronal plane (Figure 2(f)). The tendon graft connected the scaphoid and lunate at both dorsal and central regions. In the three virtual reconstruction technique simulations, the tendon grafts passing through the bone holes were represented using cylinders which were meshed with solid elements. For the tendons connecting the two bones, multiple spring elements were used (Figure 2 (d)-(f)). The stiffness of tendons grafts in the models were assumed to be the same as the dorsal SLIL stiffness.

\subsection{Cadaveric Study}

In order to validate the finite element wrist model, a cadaveric study was undertaken considering two scenarios: intact (ligament) with the hand in the neutral position and intact and SLIL sectioning under an ulnar deviated clenched fist position. Fifteen freshly frozen hand and wrist cadaveric specimens, with a mean age of 75 years (range 54 -94), were sectioned at the mid forearm. All specimens were assessed with neutral posteroanterior (PA) and lateral plain radiographs to measure SL (dorsal) gap and angle, respectively, with the hand in the neutral position following the method described in the literature $[16,17]$.

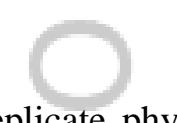

To replicate physiologic motion in the cadaver wrists, each specimen was prepared to expose the following 6 tendons/tendon groups: flexor carpi ulnaris (FCU), extensor carpi ulnaris (ECU), extensor digitorum communis (EDC), flexor digitorum superficialis (FDS), flexor digitorum profundus (FDP) and flexor pollicis longus tendon (FPL). Locking-stitches, of fibrewire, were used to create five tendon groups (FCU, ECU, FDS, FDP/FPL and EDC) to facilitate the attachment of weights. To produce the ulnar deviated clenched fist position, the specimen was fixed into a plastic cylinder, 
which was held over the edge of a table using a clamp. Loading weights of $15 \mathrm{~N}$ were attached separately to FDS, FDP/FPL, FCU and ECU while a load of 20N was applied to the EDC (Figure 3).

To create the scapholunate instability condition, the SLIL of all specimens were sectioned using a scalpel blade. The SL (dorsal) gap and angle were determined before and after sectioning under the ulnar deviated clenched fist position using PA and lateral plain radiograph stress views.

\subsection{FE Simulation of the cadaveric case}

To simulate the experimental setup, the proximal end of radius and ulna bones was fully constrained as a boundary condition (Figure 4). Two vertical loads, each of $15 \mathrm{~N}$, were applied along the $\mathrm{Z}$ axis at the proximal region of pisiform and dorsal base of the $5^{\text {th }}$ metacarpal, respectively, to simulate the loading weights stretching FCU and ECU tendons (Figure 3). The type of step employed for the Abaqus analysis was General, Static. The three loading weights used to create the clenched fist posture were applied by equally distributing the forces on the proximal end of the corresponding metacarpal bones. Accordingly, the 15N on FDS tendon and 20N on EDC tendon were distributed on the medial four metacarpal bones, while the $15 \mathrm{~N}$ on FDP/FPL tendon group was distributed on all the five metacarpal bones (Figure 4). The magnitudes of the applied forces are shown in Figure 4. The SL gaps at both volar and dorsal sides were calculated using the XZ plane (PA view) distance between the midpoints at the scapholunate articulation surface margins (Figure 5). The SL angle ( $\alpha$ ) was determined in the YZ plain (lateral view) following the description by Larsen et al. [16] (Figure 6). The SL dorsal gap and angle of the intact (ligament) and SLIL sectioning models were compared against the experimental results in order to validate the model. 
Once the model had been validated, values of the SL dorsal/volar gap and angle from all five models were used for comparison of the reconstruction techniques. The virtual reconstruction technique models were considered under the same loading and boundary conditions as those used for the cadaveric verification study (Figures 3 and 4). The virtual reconstruction surgery was first performed with the hand in the neutral position. Having performed the reconstruction surgery virtually and with the hand in the neutral position, the loading and boundary conditions were then applied to produce the ulnar deviated clenched fist posture. The effect of the three reconstruction techniques on the forces in the ligaments included in the model and the ligamentous reconstructions were also analysed.

\section{RESULTS}

\subsection{FE Model Validation}

A comparison between the predicted SL gap and angle obtained from the FE model and the experimental data is shown in Figure 7. In the neutral position, the SL gap and angle predicted by the model of the intact wrist are $1.8 \mathrm{~mm}$ and $50.8^{\circ}$, respectively, which fall well within the standard deviation of the corresponding values obtained in the cadaveric study $(2.0 \pm 0.5 \mathrm{~mm}$ for SL gap and $45.8^{\circ} \pm 9.7^{\circ}$ for SL angle, Figure 7). It was thus determined that it was reasonable to proceed to further validate the intact and SLIL sectioning model predictions for the hand in the ulnar deviated clenched fist position with the experimental data. As shown in Figure 7, the SL gap and angle of both the intact and SLIL sectioning models under the ulnar deviated clenched fist position were in relatively good agreement with the experimental data. After SLIL removal, SL gap increased in comparison to the corresponding intact case by $50.0 \%$ and $90.0 \%$ in the cadaveric and FE model predictions, respectively. Comparatively, the change of the SL angle in the ulnar deviated clenched fist position was less significant. In the cadaveric case, the mean SL angle of SLIL sectioning specimens was $6.1 \%$ lower than that of the intact, while the angle increased by $2.6 \%$ for the FE model. 
These results indicate that the SL gap is more indicative for examining SL instability for the selected wrist posture considered.

\subsection{Comparison of the Three Reconstruction Techniques}

Figure 8a and Table 3 show a comparison of the predicted SL gap at both dorsal and volar sides obtained from the five numerical models considered under the simulated ulnar deviated clenched fist position. A similar pattern in terms of SL gap was observed for both dorsal and volar sides. When the SLIL was removed, the predicted SL gap increased significantly compared to the anatomical wrist model at dorsal (90.0\% higher) and volar (55.6\% higher) sides. All the three reconstruction models significantly reduced the SL dorsal gap to closer to the magnitude of the intact model.

The difference of the SL dorsal gap of the three reconstructed models, compared against that of the intact (ligament) model, are $0.0 \%, 5.0 \%, 10.0 \%$ for Corella, SLAM and MBT methods, respectively. Compared with the intact (ligament) model, the SL volar gap of the Corella, SLAM and MBT models are $-5.6 \%, 16.7 \%$ and $33.3 \%$ different, respectively. Overall, the Corella method was more successful in reducing SL gap to close to the intact value (to within 5.6\%) followed by SLAM then MBT.

Figure $8 \mathrm{~b}$ and Table 3 show a comparison of the predicted SL angle for the intact, SLIL sectioning and the three reconstruction techniques for the simulated ulnar deviated clenched fist position. The predictions indicate that the Corella model produces an SL angle closer to that of intact (ligament) compared to the other models. All the three reconstruction models resulted in a lower SL angle compared with the intact model. 
Figure 9 shows the forces predicted by the model in the six ligaments located around the Scapholunate interosseous ligament, i.e. the Dorsal Scaphocapitate, Dorsal Lunocapitate, Volar Scaphocapitate, Long Radiolunate, Short Radiolunate and Radial Collateral ligament for the three reconstruction techniques and SLIL sectioning compared to those for the intact (ligament) case. Note, the majority of the ligaments in the model were represented as spring elements and as such force is available as output for these elements as opposed to stress, thus ligament force predictions are compared. It can be seen upon inspection of Figure 9 that the forces generated in the six ligaments located around the Scapholunate interosseous ligament in the case of the three reconstruction techniques, Corella, SLAM and MBT, are comparable to those of the intact (ligament) model, no potentially significant change or increase in force is observed.

Figure 10 shows the predicted forces in the ligamentous reconstructions for the Corella, SLAM and MBT models compared to the intact (ligament) case. For analysis purposes the forces are split into volar and dorsal section components except for in the case of the SLAM model as the technique reconstructs the volar portion of the scapholunate ligament only. It can be seen from Figure 10 that, of the two techniques that reconstruct both the dorsal and volar portions of the scapholunate ligament, the Corella method results in lower overall force in the ligamentous reconstructions and the distribution of overall force between the volar and dorsal ligamentous reconstructions, $42 \%: 58 \%$, is closer to that of the intact.

\section{DISCUSSION}

The results from the validation of the FE model showed that the predicted SL gap and angle for the intact (ligament) and SLIL sectioning cases agreed well with mean values obtained from the 
corresponding experimental results, providing a degree of confidence in the model for further practical application analysis use.

The mean values of SL gap and angle of the intact (ligament) obtained from the 15 cadaveric specimens in the neutral position were $2 \mathrm{~mm}$ and $45.8^{\circ}$, respectively. The value of SL angle $\left(45.8^{\circ} \pm 9.7^{\circ}\right)$ agreed well with previously reported values $\left(50.8^{\circ} \pm 6.7^{\circ}\right)[16]$. The resultant SL angles of SLIL sectioning wrists for the ulnar deviated clenched fist posture from both the cadaver experiments and FE simulations were within the normal range of SL angle reported, from $30^{\circ}$ to $60^{\circ}$ [23], confirming the relatively insignificant effect of SLIL on the normal rotational motion of scaphoid and lunate bones under ulnar deviation at least immediately after sectioning. This finding is consistent with the results of the previous study by Short et al [22] who investigated the ligamentous stabilizers of scaphoid and lunate bones, concluding that purely cutting the SLIL causes no statistical difference in the rotational motions of the two bones under wrist radial-ulnar deviations. Compared with SL angle, the SL gap was found to be more indicative of the SLIL injury for the selected wrist posture considered.

The experimentally determined and model predicted dorsal SL gap for the ulnar deviated clenched fist posture after full SLIL removal were all significantly greater than $3 \mathrm{~mm}$, meeting the criteria of SL dissociation [14]. The results also concur with the findings of Lee et al [17], who compared 8 different SL radiographic stress views and found that for the clenched fist views under various angles of ulnar deviation, the mean SL dorsal gaps were all greater than $3.5 \mathrm{~mm}$ after ligamentous sectioning. The predicted SL gap and angle results from the model indicate that, of the three reconstruction techniques, overall the Corella method is better able to restore SL gap and angle to closer to that of the intact (ligament) under the simulated ulnar deviated clenched fist posture, followed by the SLAM 
technique. The Corella technique restored the dorsal SL gap to that of the intact whereas SLAM was able to restore the dorsal SL gap to within $5.0 \%$ of the intact. The Corella technique resulted in a volar SL gap within $5.6 \%$ of the intact (ligament), whereas the SLAM technique was less effective, producing a gap that was some $16.7 \%$ greater than that of the intact. Regarding the SL angle, the Corella technique resulted in an angle closer to the intact.

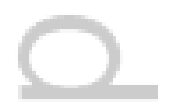

The three reconstruction techniques, Corella, SLAM and MBT, did not cause forces in the ligaments located around the Scapholunate interosseous ligament to increase or change significant compared to the intact case. The Corella method resulted in lower overall force in the ligamentous reconstructions and a distribution in overall force between the volar and dorsal ligamentous reconstructions, closer to that of the intact compared to the SLAM technique.

These results suggest the importance of augmenting the dorsal reconstruction with a volar reconstruction. Anatomically, the SLIL is divided into three distinct components: dorsal, volar, and proximal [3]. Dorsal SLIL has generally been believed to be the primary restraint among the three components of SLIL as the thickness and failure force of dorsal SLIL are more than twice that of volar SLIL, while the proximal SLIL is even thinner and fibrocartilaginous [3, 4]. Comparatively, the relative significance of volar SLIL is controversial [20]. The results of our study indicate that the contribution of volar SLIL to scapholunate stability could be important due the fact that the variability in SL gap prediction amongst the reconstruction techniques simulated was significantly greater on the volar side compared to the dorsal side.

\section{Limitations}


The simulation of kinematics of the wrist joint is always challenging due to the involvement of multibone articulations and various soft tissues. Although CT images can provide sufficient detail for the accurate modelling of bone geometries, a number of assumptions have to be made regarding geometrical modelling of cartilage and ligaments as well as the material properties for all the tissues due to inconsistencies in the literature. However, the finite element wrist model was successfully validated by comparing predicted SL gap and angle with those obtained from an in vitro cadaveric experiment conducted on intact and SLIL sectioning specimens with the hand in the neutral position and under ulnar deviated clenched fist posture, which instils a good degree of confidence in the FE model and the assumptions used therein.

The age of the female volunteer, 63 years, falls within the age range of the cadaveric specimens used in the study $(54-94)$. Although it is recognised that there exists variability in the mechanical response of biological systems, a recent review of the available literature on the effect of age and gender on wrist motion in adults found that whilst there was some variance amongst the findings, the majority of studies suggested a small, gradual decrease in range of motion with increasing age. In terms of gender difference, research has generally supported the theory that men have slightly lower wrist range of motion than women [25]. Given these findings, whilst age and gender are factors to consider, their effect on the model validation should not be significant in this case

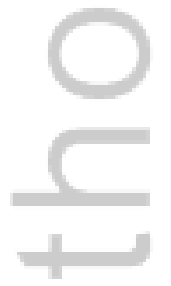

\section{REFERENCES}

1. Bajuri MN, Abdul Kadir MR, Murali MR, Kamarul T. Biomechanical analysis of the wrist arthroplasty in rheumatoid arthritis: a finite element analysis. Med Biol Eng Comput. 2013;51:175-86. 
2. Berger RA. The anatomy of the ligaments of the wrist and distal radioulnar joints. Clin Orthop Relat Res. 2001;383:32-40.

3. Berger, R.A. The gross and histologic anatomy of the scapholunate interosseous ligament. J Hand Surg Am. 1996;21:170-178.

4. Berger RA, Imeada T, Berglund L, An KN. Constraint and material properties of the subregions of the scapholunate interosseous ligament. J Hand Surg Am. 1999;24:953-962.

5. Brunelli GA, Brunelli GR. A new technique to correct carpal instability with scaphoid rotary subluxation: a preliminary report. J Hand Surg. 1995;20:S82-5.

6. Corella F, Del Cerro M, Ocampos M, Larrainzar-Garijo R. Arthroscopic ligamentoplasty of the dorsal and volar portions of the scapholunate ligament. J Hand Surg. 2013;38:2466-77.

7. Fischli, S. Simulation of wrist kinematics on the basis of a rigid body spring model. MSc. Thesis, Queen's University, Kingston, Canada; 2007.

8. Garcia-Elias M, Lluch AL, Stanley JK. Three-ligament tenodesis for the treatment of scapholunate dissociation: indications and surgical technique. J Hand Surg. 2006;31:125-34.

9. Geissler WB, Freeland AE. Arthroscopically assisted reduction of intraarticular distal radial fractures. Clin Orthop. 1996;327:125-34.

10. Gíslason MK, Stansfield B, Nash DH. Finite element model creation and stability considerations of complex biological articulation: The human wrist joint. Med Eng Phys. 2010;32:523-31.

11. Guo X, Fan Y, Li ZM. Effects of dividing the transverse carpal ligament on the mechanical behavior of the carpal bones under axial compressive load: a finite element study. Med Eng Phys. 2009;31:188-94.

12. Jones, W.A. Beware the sprained wrist. The incidence and diagnosis of scapholunate instability. J Bone Joint Surg Br. 1988;70:293-7.

13. Kijima Y, Viegas SF. Wrist anatomy and biomechanics. J Hand Surg Am. 2009;34:1555-63. 
14. Kitay A, Wolfe SW. Scapholunate instability: current concepts in diagnosis and management. J Hand Surgery Am. 2012;37: 2175-2196.

15. Kobayashi M, Berger RA, Nagy L, Linscheid RL, Uchiyama S, Ritt M, An KN. Normal kinematics of carpal bones: a three-dimensional analysis of carpal bone motion relative to the radius. J Biomech. 1997;30:787-93.

16. Larsen CF, Mathiesen FK, Lindequist S. Measurements of carpal bone angles on lateral wrist radiographs. J Hand Surg Am. 1991;16:888-93.

17. Lee SK, Desai H, Silver B, Dhaliwal G, Paksima N. Comparison of radiographic stress views for scapholunate dynamic instability in a cadaver model. J Hand Surg Am. 2011;36:1149-57.

18. Lee SK, Zlotolow DA, Sapienza A, Karia R, Yao J. Biomechanical comparison of 3 methods of scapholunate ligament reconstruction. J Hand Surg. 2014;39:643-50.

19. Nagao S, Patterson RM, Buford WL Jr, Andersen CR, Shah MA, Viegas SF. Three-dimensional description of ligamentous attachments around the lunate. J Hand Surg Am. 2005;30:685-92.

20. Rajan PV, Day CS. Scapholunate Interosseous Ligament Anatomy and Biomechanics. J Hand Surg Am. 2015;40:1692-702.

21. Savelberg HH, Kooloos JG, Huiskes R, Kauer JM. Stiffness of the ligaments of the human wrist joint. J Biomech. 1992;25:369-76.

22. Short WH, Werner FW, Green JK, Masaoka S. Biomechanical evaluation of ligamentous stabilizers of the scaphoid and lunate. J Hand Surg Am. 2002;27:991-1002.

23. Tan S, Ghumman SS, Ladouceur M, Moser TP. Carpal angles as measured on CT and MRI: can we simply translate radiographic measurements? Skeletal Radiol. 2014;43:1721-8.

24. Van Den Abbeele KL, Loh YC, Stanley JK, Trail IA. Early results of a modified Brunelli procedure for scapholunate instability. J Hand Surg. 1998;23:258-61. 
25. Norkin, C. C., White, D. J. Measurement of joint motion: a guide to goniometry $5^{\text {th }}$ Edition.

FA Davis; 2017

\section{Tables}

Table 1 Ligaments included in the model

\begin{tabular}{lll}
\hline \multicolumn{1}{c}{ Ligament } & Stiffness (N/mm) \\
\cline { 2 - 3 } & Dorsal radiocarpal & $27[1]$ \\
Radial collateral & $10[1]$ \\
Ulnar collateral & $100[1]$ \\
Radioulnar & $50[1]$ \\
Radioscaphocapitate & $50[1]$ \\
Long radiolunate & $75[1]$ \\
Short radiolunate & $75[1]$ \\
Ulnolunate & $40[1]$ \\
Ulnotriquetral & $40[1]$ \\
Radioulnar & $50[1]$ \\
Dorsal intercarpal & $128[1]$ \\
Dorsal trapeziotrapezoid & $110[1]$ \\
Dorsal capitotrapezoid & $300[1]$ \\
Dorsal capitohamate & $325[1]$ \\
Dorsal triquetrohamate & $300[1]$ \\
Dorsal lunatecapitate & $150[1]$ \\
Dorsal lunatehamate & $150[1]$ \\
Dorsal scaphocapitate & $150[1]$ \\
Volar trapeziotrapezoid & $110[7]$ \\
Volar scaphotrapezial & $150[1]$ \\
Volar scaphotrapezoidal & 150 \\
Volar scaphocapitate & $40[1]$ \\
Volar capitotrapezoid & $80[7]$ \\
& $210[7]$ \\
& $40[1]$ \\
\hline
\end{tabular}




\begin{tabular}{|c|c|c|}
\hline & Volar triquetrohamate & $300[1]$ \\
\hline & Scapholunate Dorsal & $60[4,21]$ \\
\hline & Scapholunate Volar & $30[4,21]$ \\
\hline & Scapholunate Proximal & $15[4,21]$ \\
\hline & Lunotriquetral Volar & $250[7]$ \\
\hline & Trapeziotrapezoid & 110 [7] \\
\hline & Capitotrapezoid & $300[1]$ \\
\hline & Capitohamate & $325[1]$ \\
\hline & Table 2 Model art & interaction \\
\hline & Articulations & Interaction \\
\hline & Lunate-Capitate & Contact \\
\hline & Lunate-Radius & Contact \\
\hline & Lunate-Scaphoid & Contact \\
\hline & Lunate-Triquetrum & Contact \\
\hline & Scaphoid-Capitate & Contact \\
\hline & Scaphoid-Radius & Contact \\
\hline & Scaphoid-Trapezoid & Contact \\
\hline & Scaphoid-Trapezium & Contact \\
\hline & Triquetrum-Hamate & Contact \\
\hline & Triquetrum-Pisiform & Tie \\
\hline & Radius-Ulna & Contact \\
\hline & Capitate-Metacarpals & Tie \\
\hline & Capitate-Hamate & Tie \\
\hline & Capitate-Trapezoid & Tie \\
\hline & Hamate-Metacarpals & Tie \\
\hline & Trapezoid-Trapezium & Tie \\
\hline & Trapezoid-Metacarpals & Tie \\
\hline & Trapezium-Metacarpals & Tie \\
\hline
\end{tabular}


Table 3 The predicted SL gap and angle from the five models in the ulnar deviated clenched fist posture

\begin{tabular}{cccccc}
\hline & Intact & $\begin{array}{c}\text { SLIL } \\
\text { Sectioning }\end{array}$ & Corella & SLAM & MBT \\
\hline $\begin{array}{c}\text { Dorsal SL gap } \\
(\mathrm{mm})\end{array}$ & 2.0 & 3.8 & 2.0 & 2.1 & 2.2 \\
$\begin{array}{c}\text { Volar SL gap } \\
(\mathrm{mm})\end{array}$ & 1.8 & 2.8 & 1.7 & 2.1 & 2.4 \\
$\begin{array}{c}\text { SL angle } \\
(\text { Degree })\end{array}$ & 49.7 & 51.0 & 50.0 & 46.3 & 47.1 \\
\hline
\end{tabular}




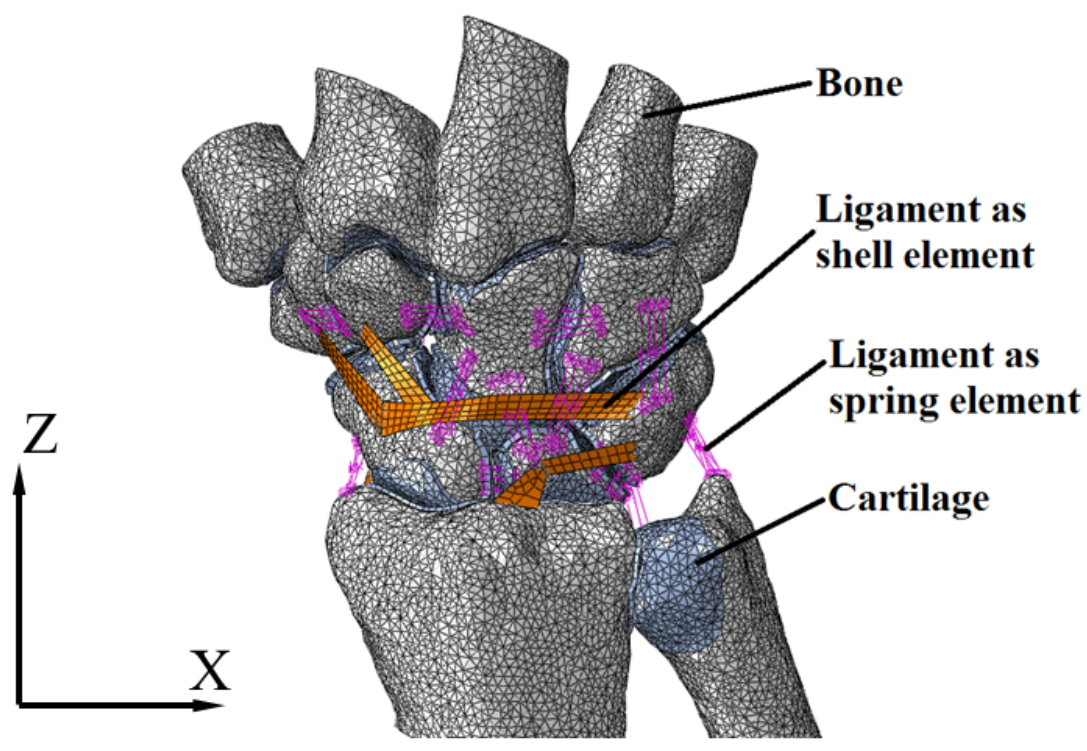

(a) Mesh

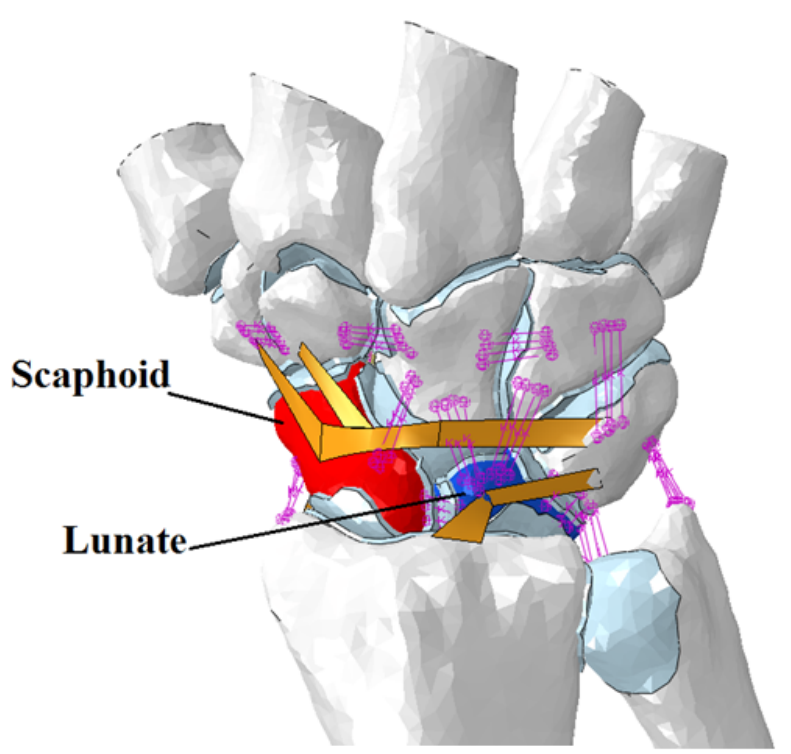

(b) Dorsal View

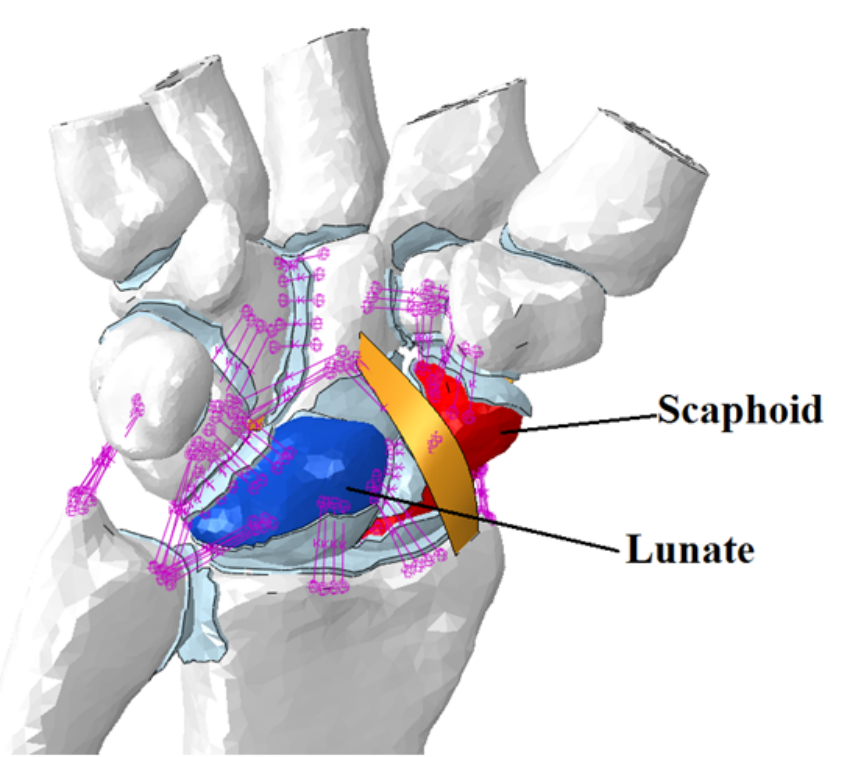

(c) Volar View

CNM_2897_F1.tif 


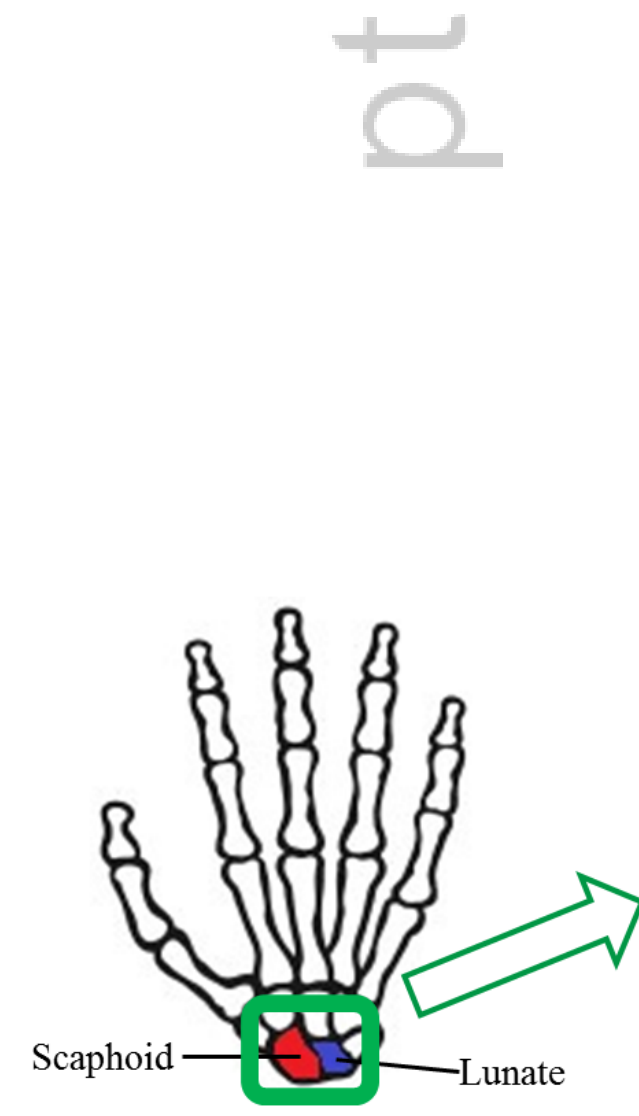

(a) The hand at neutral position

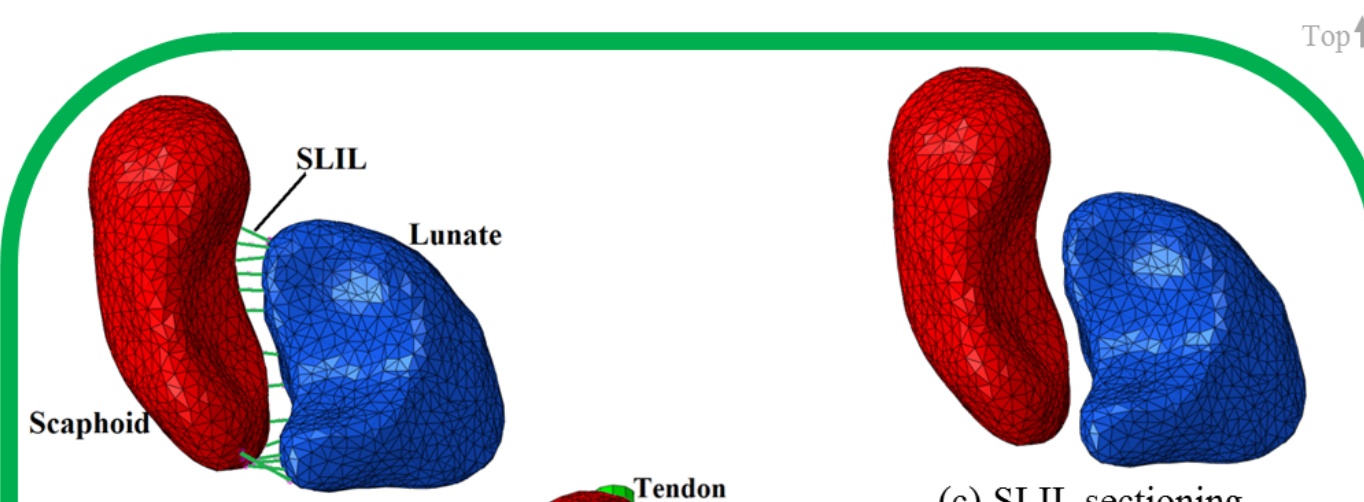

(b) Intact

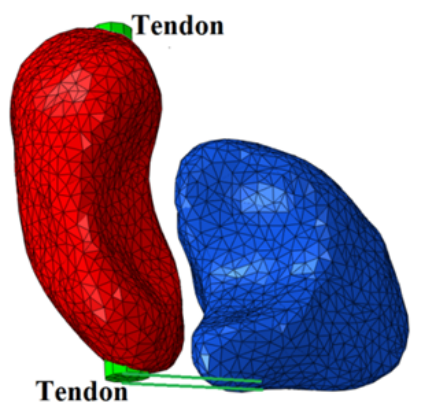

(c) SLIL sectioning

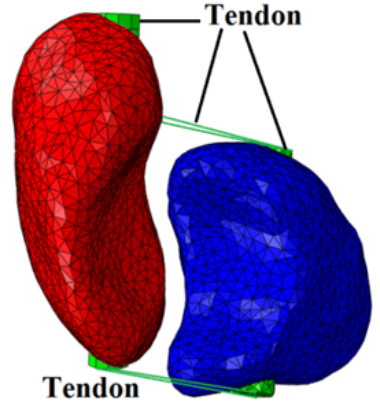

(e) Corella

(d) MBT

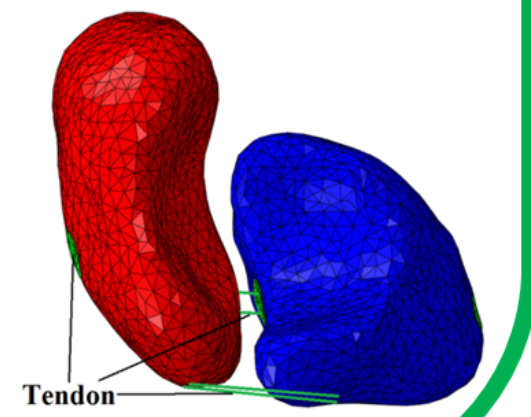

(f) SLAM 


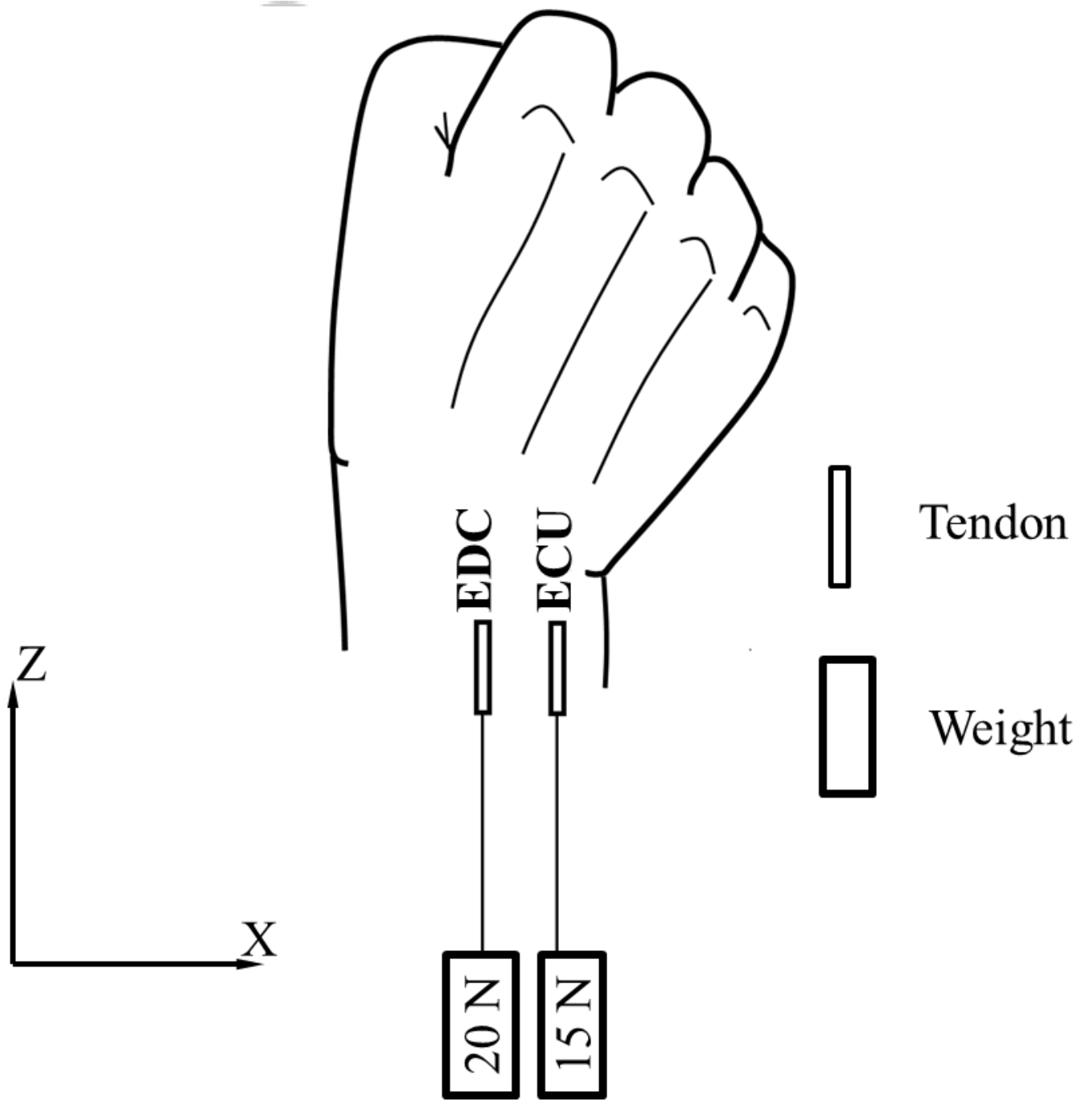

(a) Dorsal View

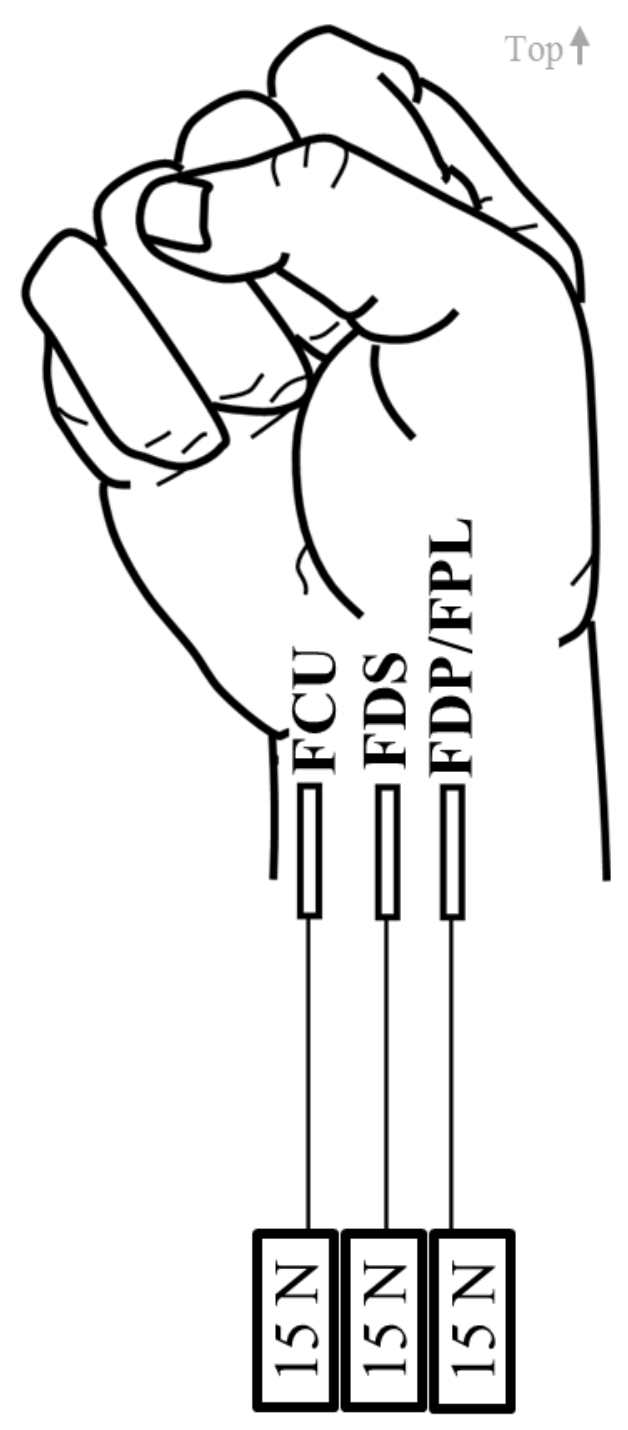

(a) Volar View

CNM_2897_F3.tif 


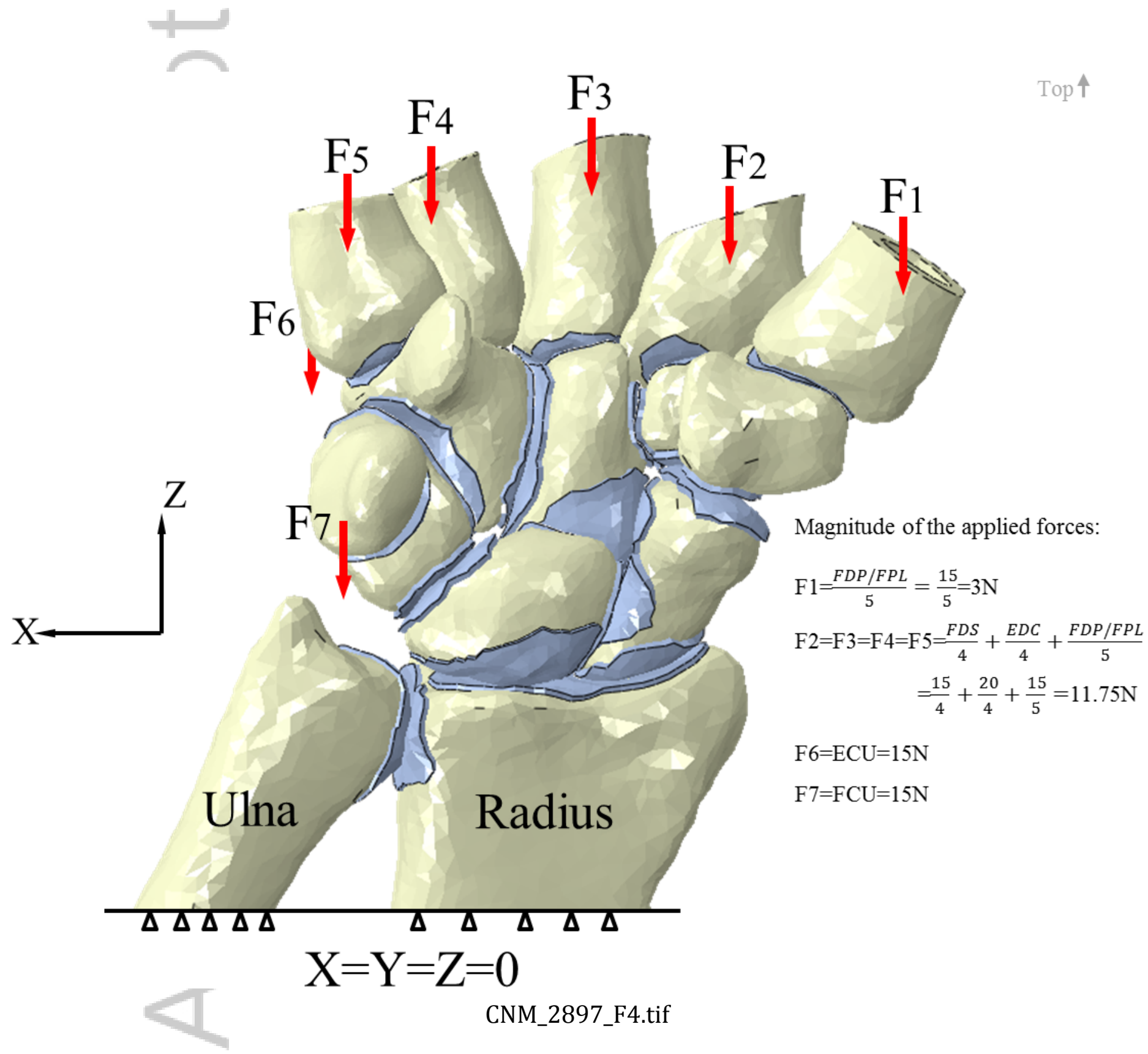

This article is protected by copyright. All rights reserved. 


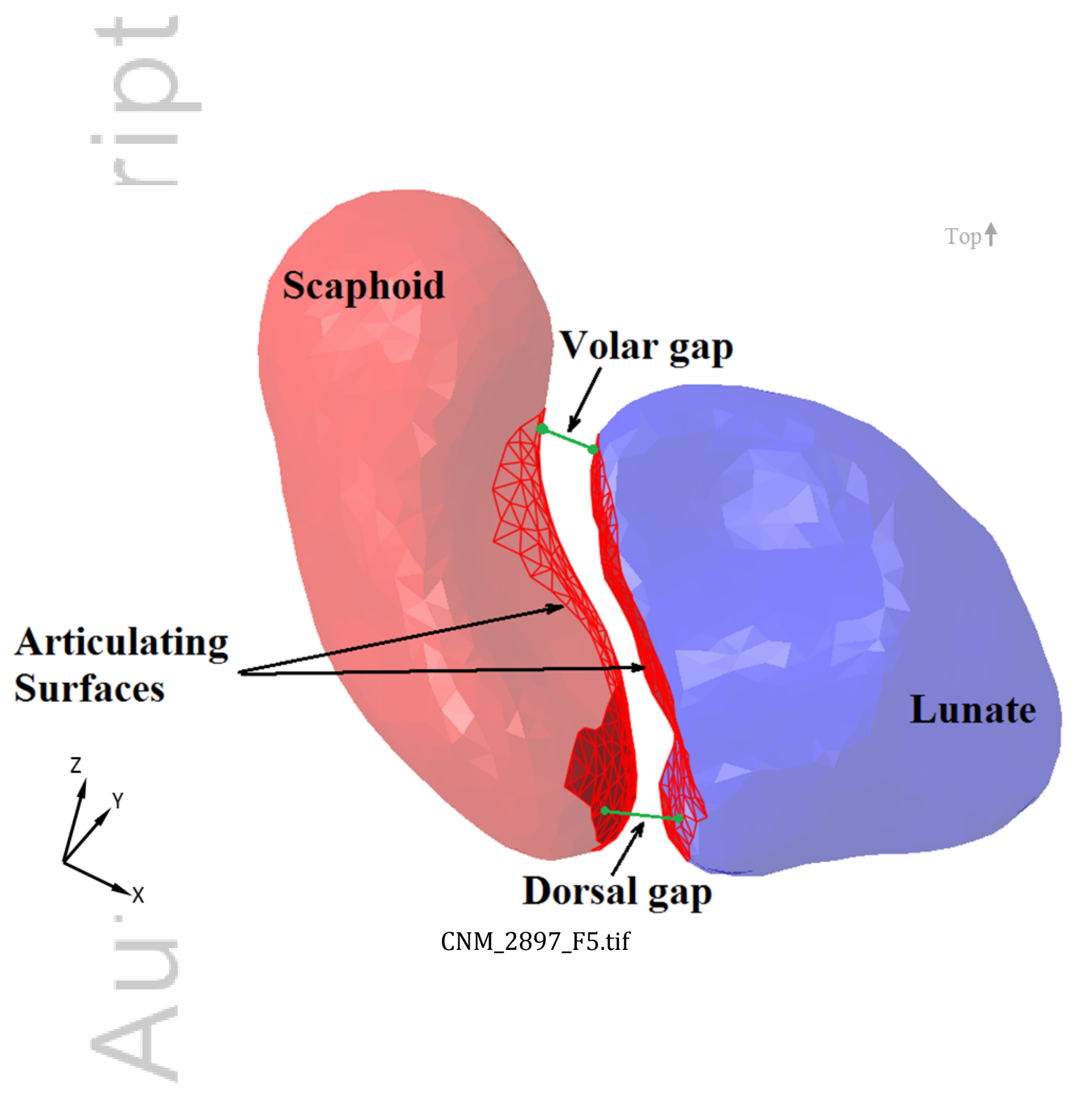

This article is protected by copyright. All rights reserved. 


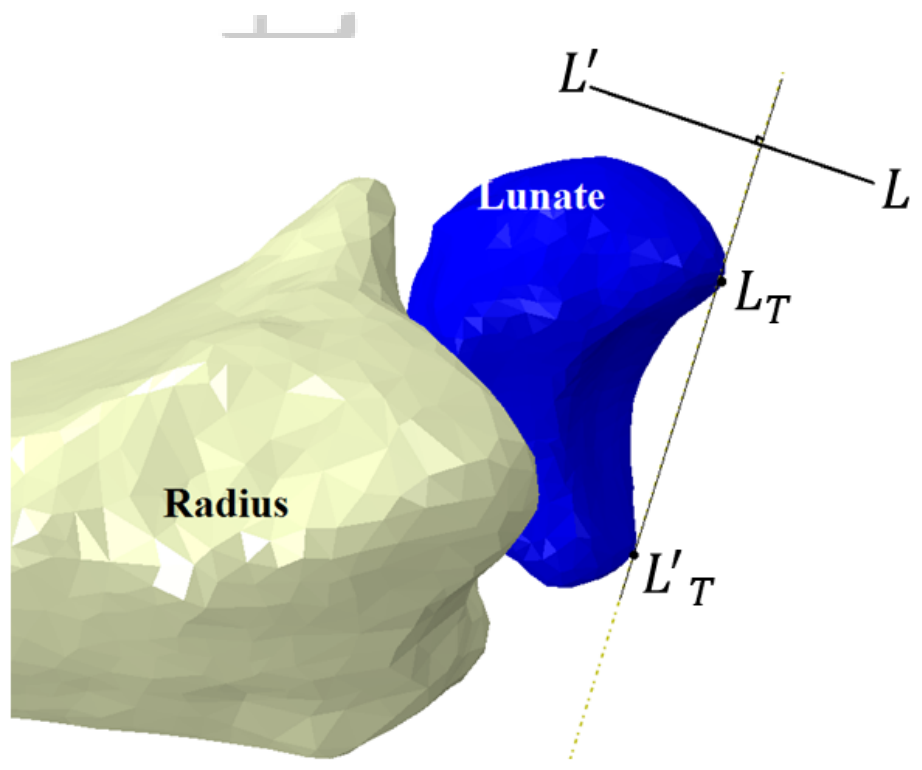

(a)

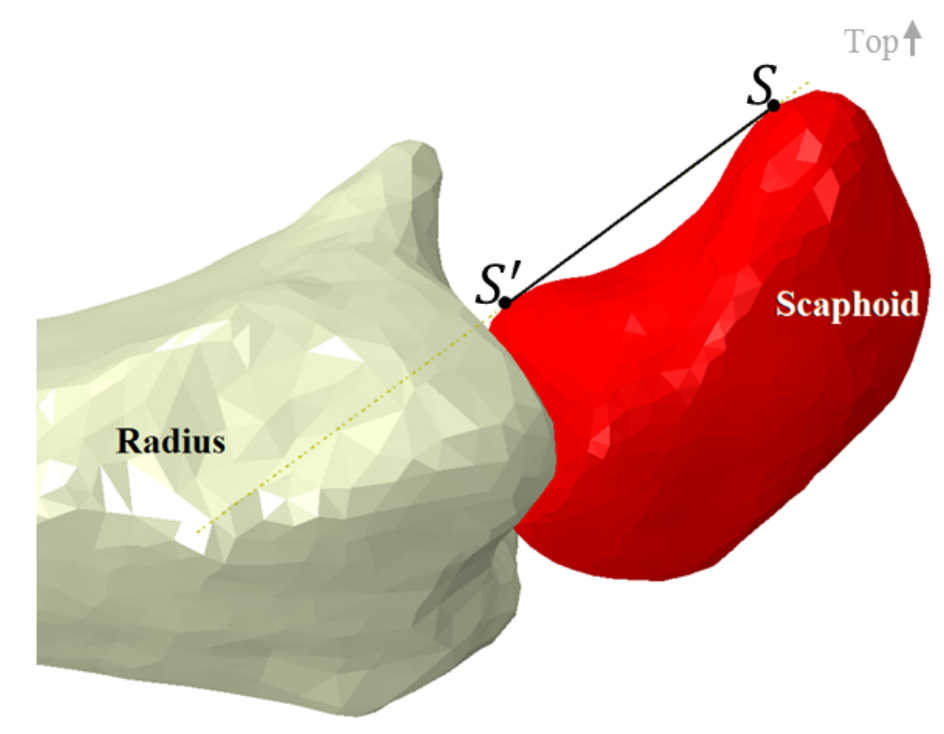

(b)
$\overline{L L^{\prime}}$ : Lunate Perpendicular $\overline{L_{T} L_{T}^{\prime}}:$ Lunate Tangent $\overline{S S^{\prime}}$ : Scaphoid Tangent $\alpha:$ SL angle

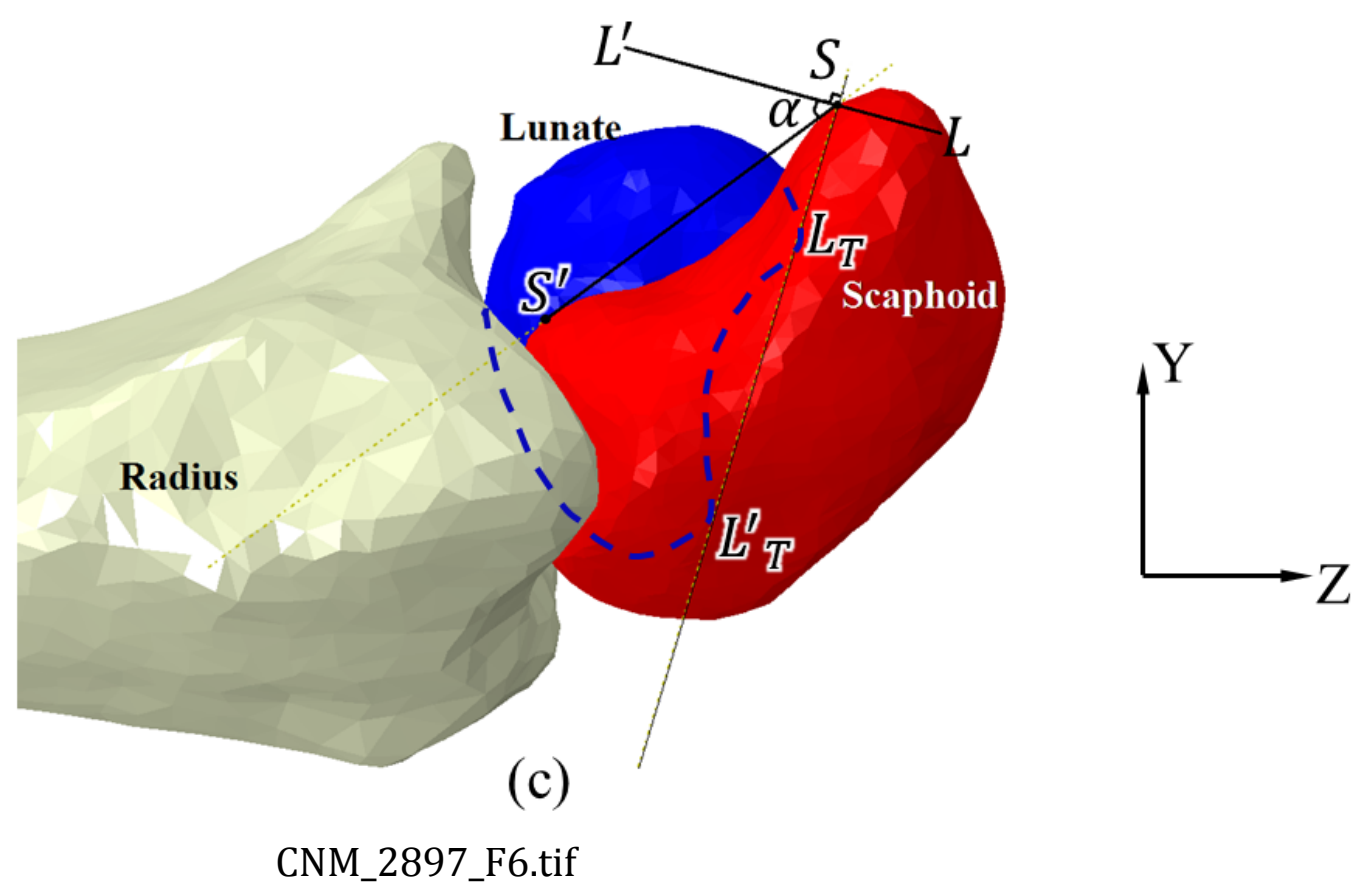


Comparisons of SL gap between FE and Experiment

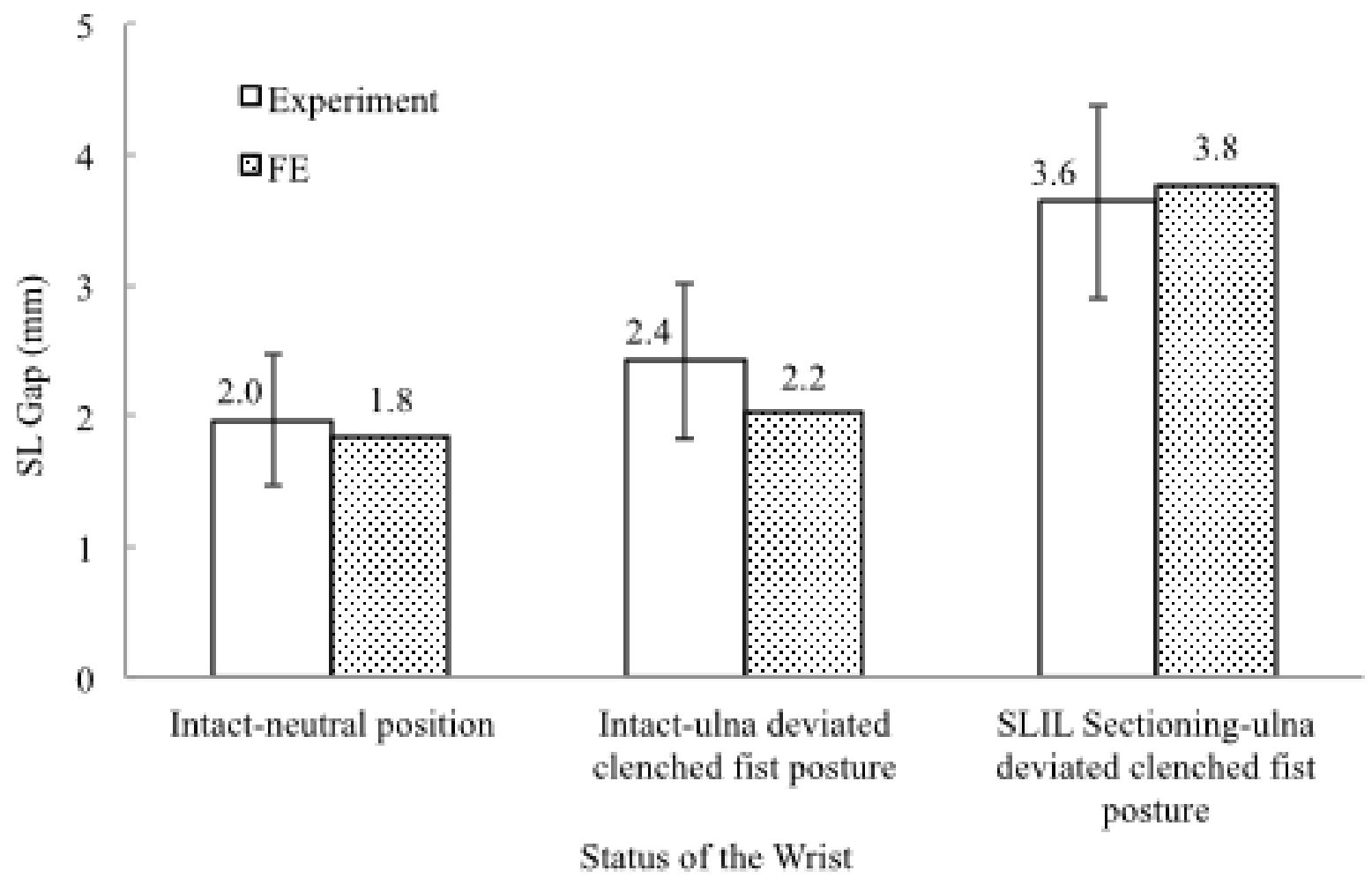

(a)

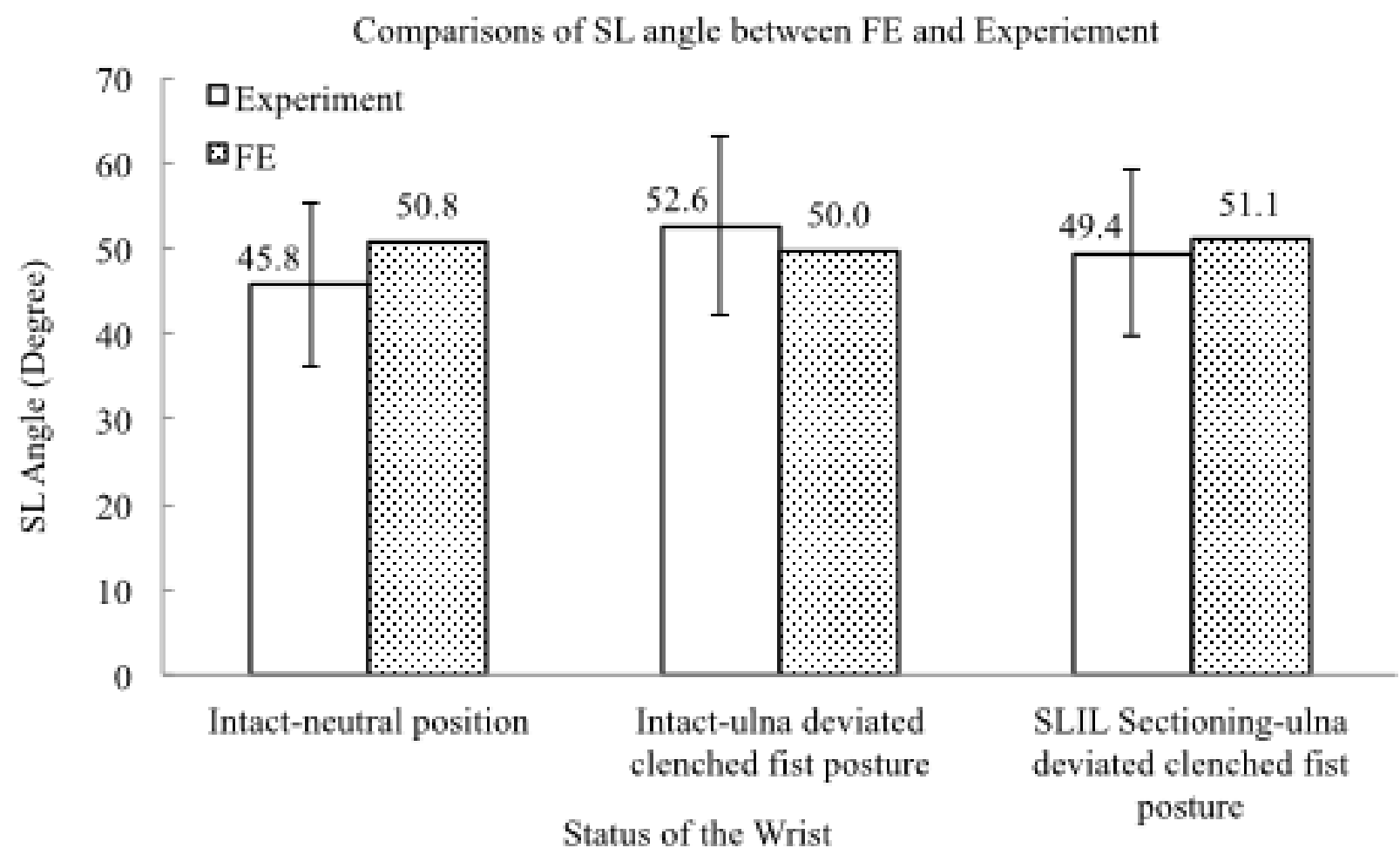

(b)

CNM_2897_F7.tif

This article is protected by copyright. All rights reserved. 


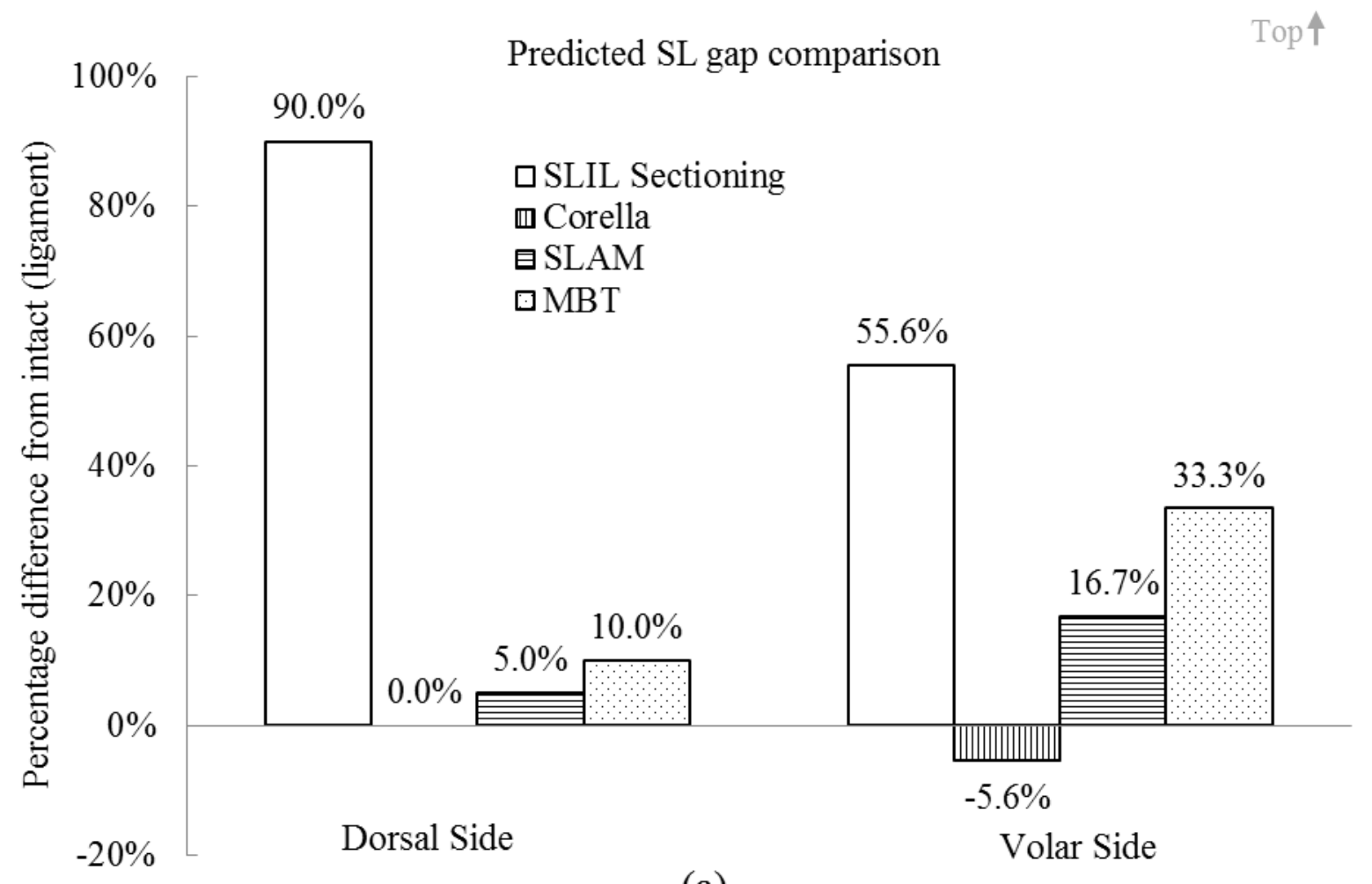

(a)

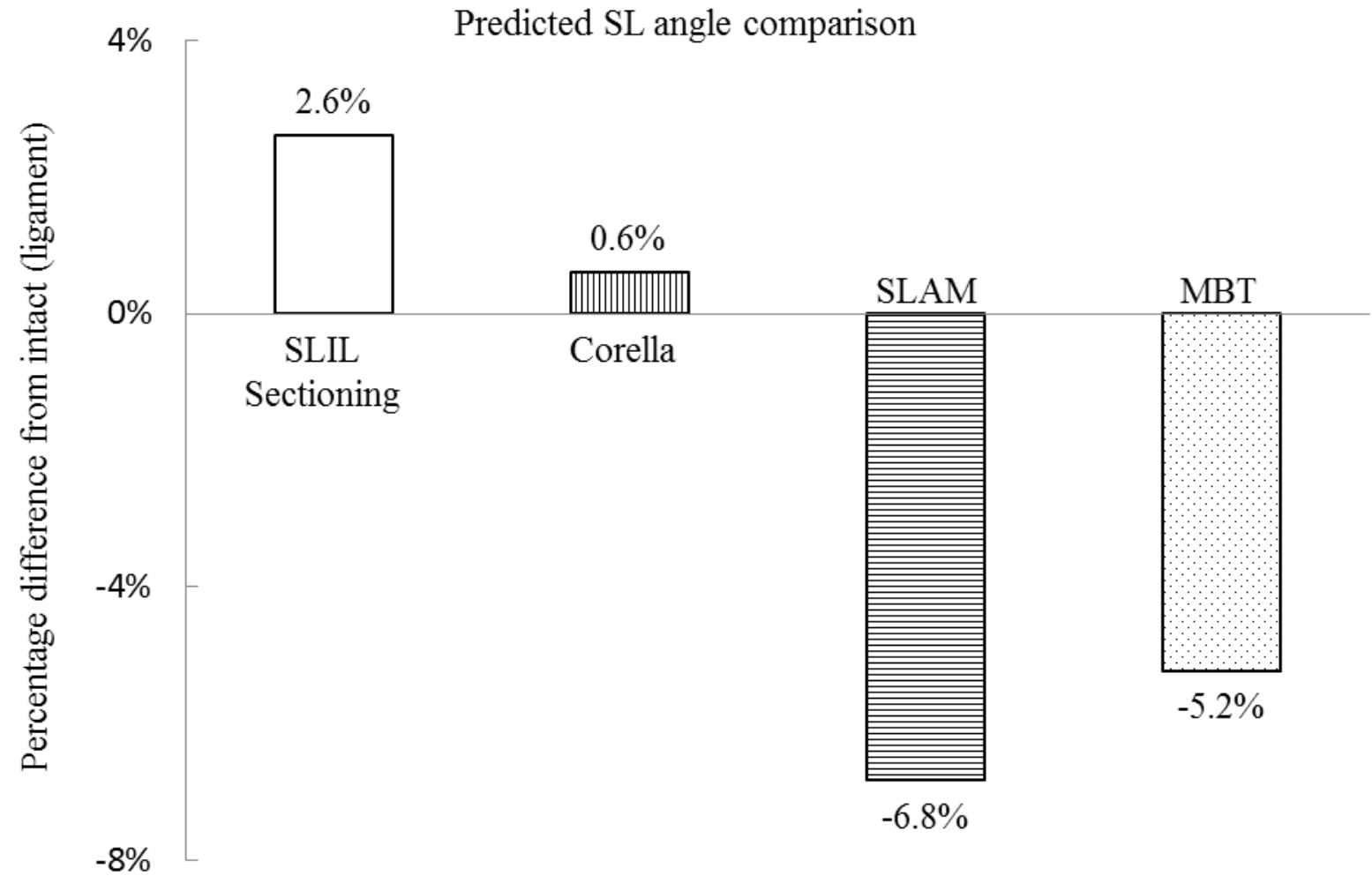

(b)

CNM_2897_F8.tif

This article is protected by copyright. All rights reserved. 

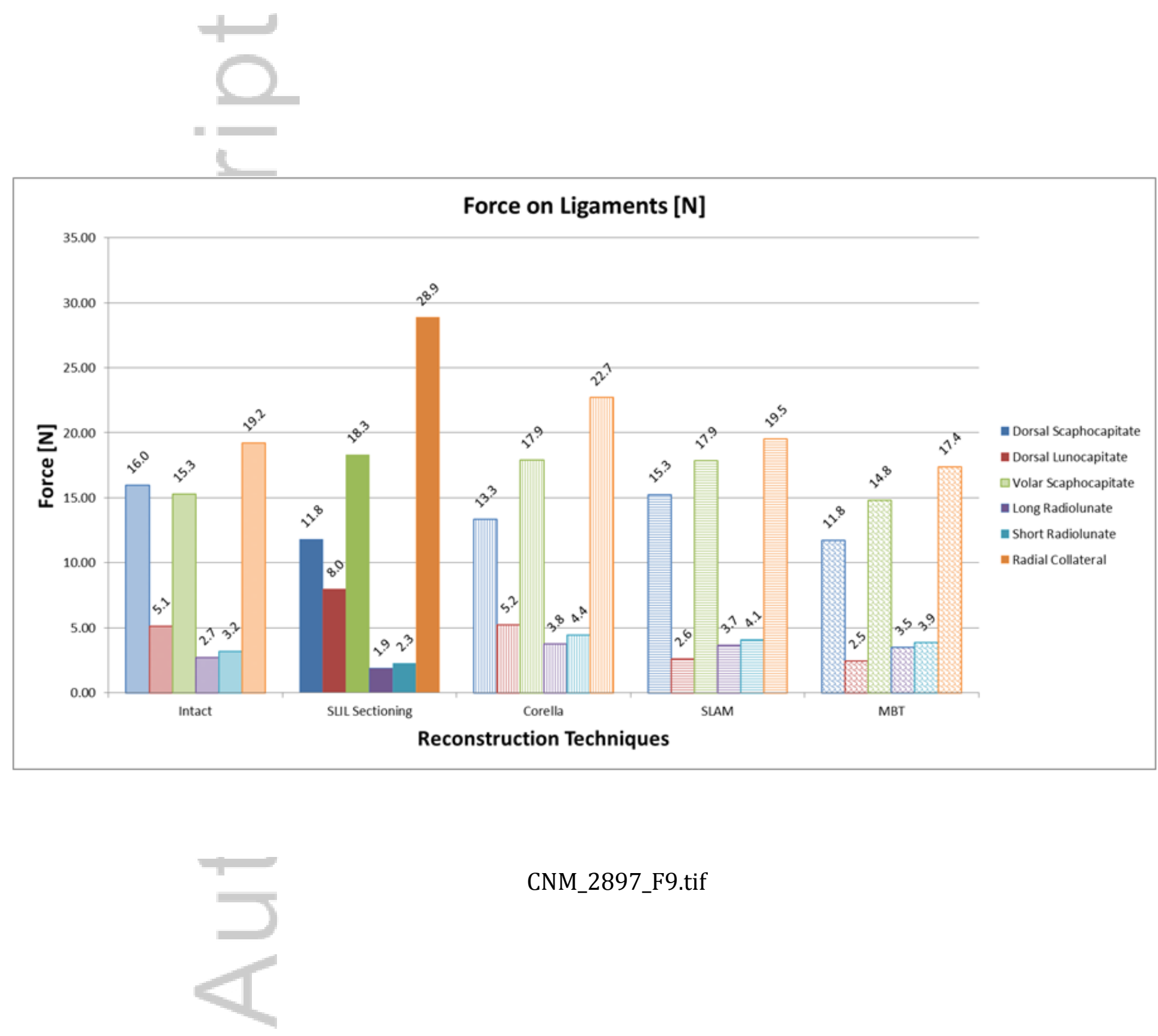

This article is protected by copyright. All rights reserved. 


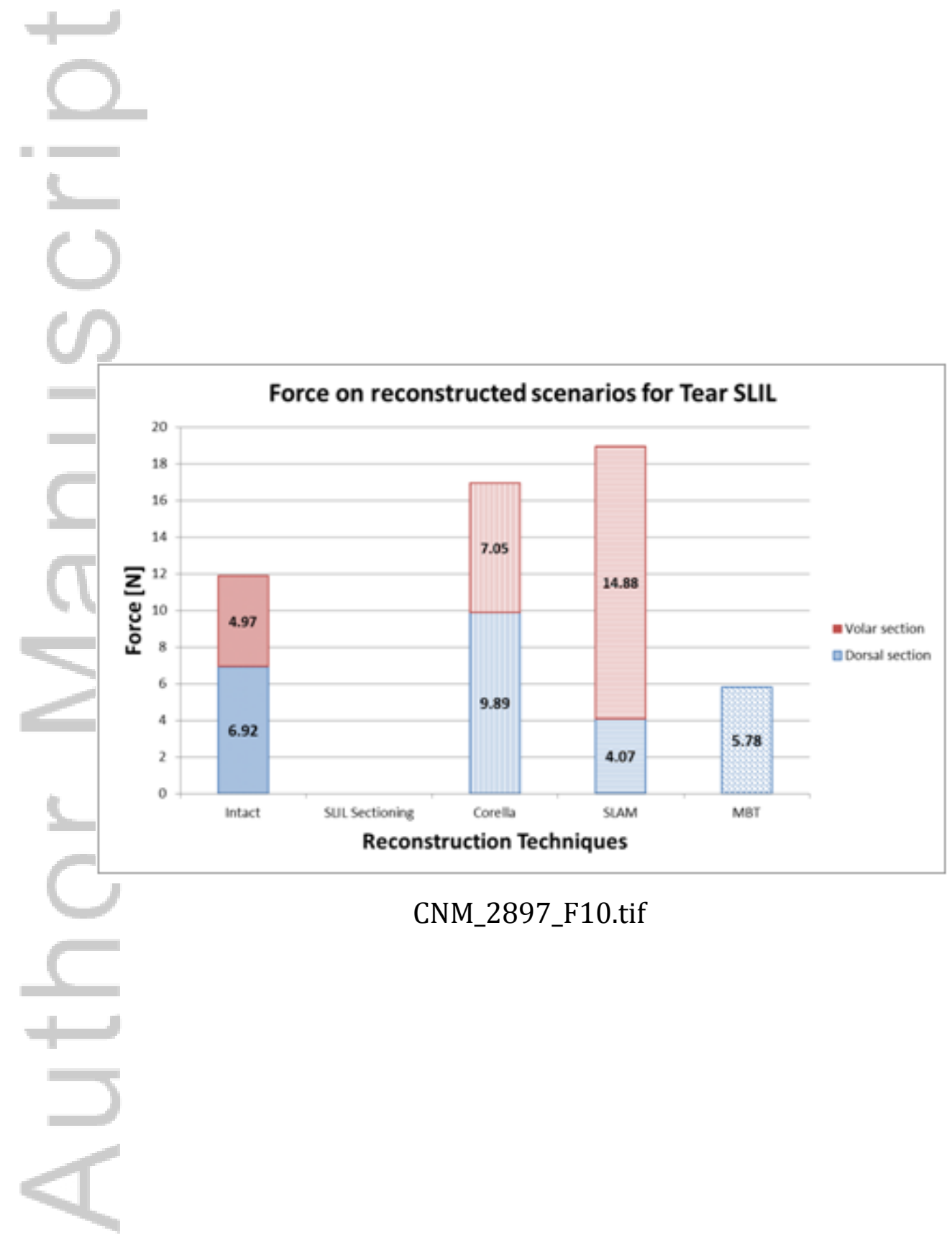

This article is protected by copyright. All rights reserved. 


\section{University Library}

\section{- M I I N E R VA \\ A gateway to Melbourne's research publications}

Minerva Access is the Institutional Repository of The University of Melbourne

Author/s:

Alonso Rasgado, T;Zhang, Q;Jimenez Cruz, D;Bailey, C;Pinder, E;Mandaleson, A;Talwalkar, S

Title:

Analysis of tenodesis techniques for treatment of scapholunate instability using the finite element method.

Date:

2017-12

Citation:

Alonso Rasgado, T., Zhang, Q., Jimenez Cruz, D., Bailey, C., Pinder, E., Mandaleson, A. \& Talwalkar, S. (2017). Analysis of tenodesis techniques for treatment of scapholunate instability using the finite element method.. Int J Numer Method Biomed Eng, 33 (12), https:// doi.org/10.1002/cnm.2897.

Persistent Link:

http://hdl.handle.net/11343/293230 